\title{
UTILIZAÇÃO DO CUSTO-META POR EMPRESAS BRASILEIRAS COMO ESTRATÉGIA DE GESTÃO: ALGUNS ESTUDOS SETORIAIS UTILIZANDO O MÉTODO DA CAUSALIDADE DE GRANGER*
}

\author{
MARCOS ANTONIO SOUZA \\ Prof. Dr. da Universidade do Vale do Rio dos Sinos - RS \\ E-mail: jumapa@mercado.unisinos.br \\ FERNANDO C. ZANELLA \\ Assistant Professor, United Arab Emirates University - United Arab Emirates \\ E-mail: f.zanella@uaeu.ac.ae
}

\section{AUSTER MOREIRA DO NASCIMENTO}

Prof. Dr. da Universidade do Vale do Rio dos Sinos - RS

E-mail: auster@mercado.unisinos.br

\section{RESUMO}

Este artigo tem como objetivo básico desenvolver, com apoio no teste de causalidade de Granger, uma técnica de pesquisa que possa avaliar, no agregado de empresas e como uma alternativa ao estudo de caso, as estratégias de preços adotadas por empresas brasileiras. Em especial, busca-se distinguir aquelas empresas que adotam o custometa como estratégia, em relação àquelas empresas que adotam o custo mais margem ou, ainda, daquelas que não apresentam uma estratégia clara de preços e custos. Quarenta e sete empresas, de oito setores distintos, foram analisadas mediante a utilização do método de causalidade de Granger. Os resultados evidenciaram a falta de estratégia com relação à gestão de preços e custos das empresas, na maioria dos casos. Em particular, a hipótese da estratégia de custo-meta predominou somente no setor de distribuição de energia elétrica. Os resultados apresentados são suscetíveis a várias contribuições e podem servir como uma agenda para futuras pesquisas.

Palavras-chave: Custo-meta; Gestão de Preço e Custo; Causalidade de Granger.

\section{ABSTRACT}

This article aims to develop, based on the Granger-causality test, a research technique to assess, in business sectors and as an alternative for case studies, the price strategies adopted by Brazilian companies. It focuses on the differentiation between those companies which use target costing as a strategy from those using the cost plus margin, or yet, from companies without a clear strategy for establishing prices and costs. Forty-seven companies from eight different segments were analyzed through Granger causality. In most cases, the results revealed a lack of strategy in terms of company price and cost management. Target costing was only predominant in the electric power distribution sector. The research results suggest possibilities for future studies.

Keywords: Target-cost; Price and Cost Management; Granger Causality.

Recebido em 25 Fev. 2005 • Aceito em 22 Jun. 2005 • 2a versão aceita em 10 Ago. 2005

* Artigo originalmente apresentado no XXVIII ENANPAD, setembro/2004, Curitiba-PR. 


\section{INTRODUÇÃO}

A estratégia do custo-meta pode ser definida, sucintamente, como uma estratégia que toma o preço estabelecido pelo mercado como parâmetro para avaliação da viabilidade da margem de lucro desejada e para a definição do custo permitido para que tal margem seja atingida.

Sakurai (1997) destaca que a determinação do custo-meta é de grande importância, por estar ligada à política estratégica da empresa. O procedimento básico envolvido na sua determinação é o de que, partindo-se de um preço de venda projetado e deduzindo o lucro meta objetivado pela empresa, tem-se o custo correspondente, ou permitido. Tal custo passa a ser a meta. Nesse sentido, os gestores devem assegurar que os custos ocorram em um nível que viabilize atender tais indicadores.

Tem-se, então, que o custo-meta surgiu como um elemento integrante da gestão estratégica empresarial, visando à adaptação, entre outros, aos seguintes elementos representativos da nova realidade: [1] maior variabilidade e personificação do mix de produtos, [2] redução do ciclo de vida dos produtos, [3] adoção de novas tecnologias de produção, [4] aumento do grau de acirramento da concorrência e da exigência de clientes, e [5] necessidade de competitividade global.

Pode-se dizer que o tradicional posicionamento das empresas brasileiras caracteriza-se pela adoção da estratégia de custo mais margem, ou adição de uma margem de lucro aos custos, resultando no preço praticado pela empresa. Tal procedimento é uma pratica estreitamente relacionada à falta de competitividade em muitos setores e, também, ao fechamento da economia brasileira a mercados globais.

Mundialmente, a competitividade tem aumentado. Inovações tecnológicas, fusões com o objetivo de reduzir custos e novas estratégias competitivas, abundam. Recentemente, as empresas brasileiras têm sido forçadas a implementar novas práticas de gestão para se manterem no mercado.

No entanto, o que se indaga é: em que extensão as novas práticas têm sido utilizadas pelas empresas brasileiras? Se utilizadas, uma segunda indagação surge: até que ponto são bem sucedidas em sua implementação? Focado na estratégia do custo-meta, este estudo procura contribuir na busca de respostas a tais questionamentos.

Tanto no contexto mundial quanto no nacional essas questões têm sido respondidas, em geral, com estudos de caso. Sabe-se que as empresas japonesas adotam com mais freqüência o custo- meta do que, por exemplo, as norte-americanas. ${ }^{1}$ Já a resposta para as brasileiras ainda carece de estudos específicos.

Para viabilizar sua contribuição, este trabalho propõe-se a desenvolver uma técnica de pesquisa que busca, de forma agregada, ao invés de estudos de casos, identificar qual seria a estratégia de preços adotada pelas empresas constituintes de alguns setores. O método de análise é o da causalidade de Granger. Esse método ganhou destaque mundial após Cleve Granger receber o Prêmio Nobel de Economia em 2003. O método é discutido mais detalhadamente na seção três.

Com o intuito de testar se as empresas brasileiras adotam alguma estratégia de preços, mais especificamente o custo-meta, quatro hipóteses serão levantadas e testadas pelo método de Granger.

As hipóteses a serem testadas são as seguintes:

1) o preço dos produtos vendidos determina os custos de produção, isto é, a relação é unicausal no sentido de que preço causa custo, ou custo-meta $(\mathrm{H} 1)$;

2) o custo dos produtos vendidos determina o ajuste dos preços, isto é, há uma relação unicausal no sentido de que custo causa preço, ou hipótese do poder de mercado (custo mais margem) da empresa (H2);

3) variáveis defasadas de preços determinam o ajuste nos custos dos produtos e variáveis defasadas dos custos determinam o ajuste dos preços dos produtos vendidos. Essa é a hipótese da causalidade bilateral ou interdependência entre preços e custos $(\mathrm{H} 3)$;

4) não existe relação estatisticamente significante entre as variáveis defasadas, sejam elas de preço ou custo dos produtos vendidos. Essa é a hipótese da independência, ou indeterminação, entre preço e custo $(\mathrm{H} 4)$. Esta hipótese não sugere que inexista relação entre preço e custo, mas sim que não foi possível constatar um padrão, estatisticamente significante, dessas relações.

\section{CUSTO-META}

Na essência, o custo-meta tem como premissa que dado um preço ditado pelo mercado e um objetivo de lucro, os gestores devem assegurar custos em um nível que viabilize atender tais indicadores. E mais, que esse processo de análise torna-se mais eficaz quando ocorre ainda na fase de projeto do produto.

\footnotetext{
${ }^{1}$ Borgerñas e Fridh (2003) realizaram um estudo para verificar a utilização do targeting cost pelas empresas de manufatura na Suécia.
} 
Horngren et al. (1996), também, expressam esse entendimento ao afirmarem que o custo-meta é uma estratégia que a empresa adota com o objetivo de viabilizar uma adequada margem de lucro, considerando o preço aceito pelo mercado e um adequado custo, estabelecidos quando do planejamento e desenvolvimento do produto ou serviço, com atributos que atendam às exigências dos clientes.

Tem-se, então, que o custo-meta incorpora a idéia de que o custo do produto é prioritariamente estabelecido e controlado na sua fase de projeto.

Essa ênfase na fase de projeto do produto decorreu do reconhecimento de que, substancialmente, o custo do produto é determinado quando do seu desenvolvimento. Portanto, durante a fase de fabricação, melhorias são possíveis e devem ser buscadas; porém, sem efeitos de grande magnitude. Reduções significativas somente são viabilizadas por meio de reprojeto do produto.

Tal reconhecimento tem sido, por exemplo, destacado por Cooper e Slagmulder (1997). Eles enfatizam que, uma vez que o produto é projetado, a maior parte dos custos já estão comprometidos. Segundo esses autores, alguns estudos estimam que $90 \%$ a $95 \%$ dos custos são estabelecidos na fase de projeto do produto.

Sakurai (1997:51), também, reconhece a importância do custo-meta na gestão de custo, ao afirmar que: "os esforços de redução de custos nos estágios de planejamento e de desenho tornaram-se cruciais para a sobrevivência das empresas nos tempos atuais de grande concorrência, porque cerca de $90 \%$ dos custos são determinados no estágio do planejamento".

Esse reconhecimento traz em sua amplitude, conforme Sakurai (1997), a interpretação de que o custo-meta seja considerado um instrumento de gerenciamento estratégico de custos, para planejamento de lucro e para redução de custo.

Nessa mesma linha de raciocínio, Cooper e Chew (1996:95) afirmam que: "De fato, algumas companhias japonesas classificam o custo-meta como uma ferramenta de gerenciamento do lucro, mais do que como uma ferramenta de controle de custo".

Sakurai (1997) destaca que a determinação do custo-meta é de grande importância, por estar ligada à política estratégica da empresa. O procedimento básico envolvido na sua determinação é o de que, partindo-se de um preço de venda projetado e deduzindo o lucro meta objetivado pela empresa, tem-se o custo correspondente, ou permitido. Tal custo passa a ser a meta.
A existência do custo-meta não significa, entretanto, a falta de compromisso com possíveis meIhorias futuras, passíveis de serem obtidas durante a fase de real fabricação do produto. Esse compromisso é que dá origem a uma outra técnica, de origem japonesa, denominada Kaizen, ou processo de melhoria contínua.

\section{A CAUSALIDADE DE GRANGER}

O teste de causalidade, proposto neste trabaIho, visa superar as limitações do uso de simples correlações entre variáveis. Essa distinção é de fundamental importância porque correlação não implica causalidade em algum sentido.

A esse respeito manifestam-se Kendall e Stuart (1961) quando afirmam que a identificação de uma relação estatística entre duas variáveis, por mais forte que seja, não pode nunca estabelecer uma relação causal entre elas. Por exemplo, o aumento da base monetária (BM) de um país, provavelmente, terá uma alta correlação com o crescimento do produto interno bruto (PIB). Não obstante, essa correlação não produz qualquer tipo de evidência se um acréscimo da BM determina um maior crescimento do PIB, ou o exatamente oposto ocorre. Tampouco determina se existe um sentido bicausal (determinados conjuntamente) entre as variáveis em estudo, no caso BM e PIB.

Diversos estudos têm sido realizados utilizando a causalidade de Granger, principalmente no campo da economia. São alguns exemplos: [1] o estudo de Carneiro e Faria (1996), analisando a precedência temporal do salário mínimo sobre os outros salários da economia; [2] o estudo de Ferreira (1993), verificando se mudanças na taxa de câmbio precedem mudanças no saldo da balança comercial; [3] o estudo de Baffes e Shah (1994), que investigou a natureza da causalidade entre gastos do governo e receitas tributárias para Argentina, Brasil e Chile; [4] o estudo de Bone (2003), analisando a causalidade entre as ações da Petrobrás Holding e o Ibovespa entre 1994 e 2002.

O teste de causalidade também tem sido objeto de estudos envolvendo as variáveis contábeis de custo e preço. ${ }^{2}$

A explícita relação entre as variáveis custo e preço pode ser encontrada nos Princípios Fundamentais de Contabilidade (PFC). Ao discorrer sobre os PFC, particularmente sobre o princípio da competência, o Conselho Federal de Contabilidade

${ }^{2}$ Um exemplo de teste de causalidade de Granger com as variáveis preço e custo é o de Bahia (2000). Nesse trabalho, entretanto, o autor utiliza dados agregados da indústria ao invés de separar por empresas. Além disso, o objetivo também foi distinto. 
(2000, p. 58) destaca que "o caminho correto está na proporcionalização da receita aos esforços despendidos, usualmente expressos por custos - reais ou estimados - ou etapas vencidas".

A utilização de dados contábeis é particularmente sensível a esse tipo de problema. A maioria das informações contábeis são correlacionadas entre si. Isso advém do fato de que, ao se trabalhar com um determinado dado, esse irá afetar outras informações do mesmo balanço: é o método das partidas dobradas.
Conseqüentemente, a maior parte das informações não podem ser trabalhadas contabilometricamente sem a existência prévia de uma teoria. De outra forma, os resultados obtidos são redundantes estatística e teoricamente.

O teste de Granger (1969) ${ }^{3}$ procura determinar o sentido causal entre duas variáveis. Basicamente, o teste estipula que X "Granger" causa $Y$ se valores passados de $X$ ajudam a prever o valor presente de Y. O teste é formulado como segue:

$$
\begin{aligned}
& \text { 1) } Y_{t}=\beta_{0}+\beta_{1} Y_{t-1}+\ldots+\beta_{i} Y_{t-i}+\gamma_{1} X_{t-1}+\ldots+\gamma_{i} X_{t-i}+\mu_{t} \\
& \text { 2) } X_{t}=\delta_{0}+\delta_{1} X_{t-1}+\ldots+\delta_{i} X_{t-i}+\lambda_{1} Y_{t-1}+\ldots+\lambda_{i} Y_{t-i}+\mu_{t}
\end{aligned}
$$

O método é acompanhado do teste F-estatístico (wald statistics) para verificar se os coeficientes das variáveis defasadas são conjuntamente inválidos. Por exemplo, se $\gamma 1=\ldots=\gamma \dot{i}=0$, então valores passados de $X$ não explicam o comportamento atual de $Y$. Se $\lambda 1=\ldots=\lambda i=0$, então valores passados de $Y$ não explicam o comportamento atual de $X$. O teste consiste em dividir a amostra em dois grupos de observações $\left(n=n_{1}+n_{2}\right)$. Depois, executa-se uma regressão para cada grupo e separa-se a soma dos quadrados dos resíduos $\left(\mathrm{SSE}_{1}\right.$ e $\left.\mathrm{SSE}_{2}\right)$. SSE mais $\mathrm{SSE}_{2}$ é conhecido como a soma dos quadrados dos erros sem restrição. Também, executa-se a regressão para os dados agrupados e obtém-se novamente os resíduos (SSEr), os quais são chamados de soma dos quadrados dos erros restrita. Executase o teste $\mathrm{F}$ conforme descrito abaixo: ${ }^{4}$

$$
F=\frac{\left[S S E_{r}-\left(S S E_{1}+S S E_{2}\right)\right] / k}{\left(S S E_{1}+S S E_{2}\right) /(n-2 k)}
$$

em que k é o número de termos defasados utilizados e (n-2k) representa os graus de liberdade. Se $\mathrm{F}_{\text {estatistico }}>\mathrm{F}_{\mathrm{k}, \mathrm{n}-2 \mathrm{k}}$ rejeita-se a hipótese nula de que não há causalidade no modelo. Ou simplesmente, que foi detectada causalidade no teste.

Esse método permite que sejam testadas as seguintes hipóteses:

1. valores defasados de $X$ ajudam a explicar o valor atual de $Y$, isto é, a relação é unidirecional, ou unicausal, de $X$ para $Y$;

2. valores defasados de $Y$ ajudam a explicar o valor atual de $X$, isto é, a relação é unidirecional, ou unicausal, de $Y$ para $X$;
3. valores defasados de $X$ explicam o $Y$ atual e valores defasados $Y$ explicam o $X$ atual, isto é, eles são determinados simultaneamente;

4. valores defasados de $X$ não determinam o $Y$ atual e valores defasados de $Y$ não determinam o $\mathrm{X}$ atual, isto é, as duas séries de tempo são independentes.

\section{COLETA E TRATAMENTO INICIAL DOS DADOS}

Os dados foram obtidos junto ao software Economática ${ }^{\mathrm{TM}}$. No total, 47 empresas foram testadas para a existência da causalidade de Granger entre as variáveis preço e custo dos produtos vendidos.

Como já referido, o custo-meta é tratado como um instrumento de planejamento. Considera-se, neste estudo, que os dados expressos nas demonstrações contábeis, por conseguinte, reais e históricos, refletem a execução de atividades delineadas em seus respectivos planejamentos. Portanto, se no planejamento as empresas projetaram utilizar o custometa, há relação entre eles - planejados e realizados.

Especificamente, selecionaram-se os valores registrados junto aos balanços trimestrais e a demonstração de resultados do exercício.

Os itens selecionados foram: [1] receita operacional líquida e [2] custo dos produtos vendidos. Para se obter preço e custo unitário de vendas bastaria dividir essas séries pela quantidade vendida, informação não disponível. Entretanto, justamente pelo fato de que as duas séries deveriam ser divididas pela mesma variável, quantidade, isso não afeta o resultado do teste de causalidade de Granger. No caso deste trabalho, as séries, em geral, foram

${ }^{3}$ Posteriormente, o teste de causalidade foi aprimorado com a possibilidade de utilização dos VEC (vectors of error correction models). A esse respeito, ver Engle and Granger (1987).

${ }^{4}$ Ver Pindyck e Rubinfeld (1998) 
constituídas de 36 trimestres, de março de 1995 até dezembro de 2003.

Antes de se trabalhar com dados de séries temporais é necessário testar para existência de raiz unitária I (1), ou seja, para verificar se existe uma quebra na tendência das séries. A existência da "quebra" indica que as séries são não-estacionárias. Conseqüentemente, é imprescindível torná-las estacionárias para evitar a obtenção de resultados espúrios. O detreding, na maioria das vezes, é obtido através das primeiras diferenças. ${ }^{5} \mathrm{O}$ teste de raiz unitária utilizado foi o Augmented Dickey-Fuller, executado com o software Eviews 4.1 $1^{\mathrm{TM}}$.

O número de defasagens utilizadas variou conforme a inspeção correlograma. Em geral, as defasagens utilizadas foram de 3 ou 4 períodos. Na totalidade dos casos constatou-se a existência de raiz unitária, a qual foi corrigida - as séries tornaram-se estacionárias I (0) - com a obtenção das primeiras diferenças. Antes, ainda, as séries foram somente trabalhadas após serem obtidos os logaritmos.

\section{LIMITAÇÕES DO ESTUDO}

Conforme destacado na Introdução deste estudo, a técnica de pesquisa utilizada objetiva identificar qual a estratégia de preços adotada pelas empresas pesquisadas. Ao utilizar as demonstrações contábeis publicadas como fonte de dados, tem-se a restrição de se trabalhar com dados disponibilizados de forma agregada. É de tal agregação de dados que decorrem as principais limitações deste estudo, das quais destacam-se as seguintes:

a) a influência do mix de produtos na análise, dado que o custo-meta é atribuído por produto e não para o conjunto de produtos;

b) dificuldade de evidenciar que a empresa pode estar adotando o custo-meta para alguns produtos e não para outros;

c) o custo dos produtos vendidos (CPV) é composto de elementos fixos e variáveis, os quais apresentam oscilações diferentes em relação à receita líquida $(\mathrm{RL})$; a não consideração de tais oscilações pode causar distorções no estudo;

d) as variações de preços afetam diferentemente o CPV e a RL, dificultando inferências quanto ao uso do custo-meta pelas empresas com base nessas duas variáveis tratadas de forma agregada;

e) a estratégia do custo-meta pressupõe a adequação de custos e receitas ao longo de todo o ciclo de vida do produto; portanto, há necessidade de confirmação da consistência desse ciclo com o período das demonstrações contábeis utilizadas;

f) excetuando-se as situações em que as empresas trabalham com um único produto, a utilização de demonstrações contábeis com valores agregados falha em considerar isso como uma realidade de todas as empresas pesquisadas;

g) o custeio-meta, entendido como o processo de estabelecimento do custo-meta, envolve diversos aspectos de natureza qualitativa, de difícil verificação por meio de demonstrações contábeis; tais aspectos envolvem desde estratégias, objetivos estabelecidos, procedimentos preparatórios, autonomia para decisões, prazo utilizado, modelo adotado, custos incluídos ou excluídos etc (SAKURAI, 1997).

Nota-se, pela natureza das limitações citadas, com exceção da última, que elas decorrem mais da forma como as demonstrações contábeis são divulgadas do que propriamente da técnica utilizada. Portanto, o avanço no maior detalhamento e transparência de tais demonstrações possibilitará explorar o uso da técnica de causalidade em maior amplitude.

Cabe destacar que a divulgação das demonstrações contábeis da forma tão agregada como ocorre atualmente, prejudica a aplicação de outras técnicas no conteúdo e amplitude como teoricamente elas são desenvolvidas. Nesse sentido, por exemplo, a tradicional análise econômica e financeira de balanço é uma técnica que é sensivelmente prejudicada em seu uso.

Acredita-se que as limitações aqui indicadas, ao contrário de invalidar o uso da técnica proposta, deve servir como um indicador da necessidade de maior transparência nas informações disponibilizadas pelas demonstrações contábeis, assim como alertar o seu usuário quanto aos cuidados que deve haver na análise, interpretação e uso das informações oferecidas.

A proposta ora apresentada como forma de busca por informações contábeis úteis ao processo gerencial das empresas representa, também, uma iniciativa de explicitar as limitações a serem superadas e direcionar estudos com essa finalidade, dada a importância de tais informações.

Essa importância e utilidade da informação contábil para fins estratégicos e operacionais também é reconhecida por Porter (1990). Especifica-

${ }^{5}$ Sobre isso, ver Enders (1995:176-181) 
mente com relação a custos e sua gestão estratégica, Porter enfatiza a utilidade de se conhecerem, mesmo que de forma estimada, os custos dos concorrentes, seja para avaliar o posicionamento deles e a partir daí desenvolverem-se estratégias competitivas, seja para selecionar concorrentes para futuras incorporações ou até mesmo para o estabelecimento de parcerias estratégicas.

\section{RESULTADOS DOS TESTES E ANÁLISES}

As 47 empresas foram divididas em 8 grupos. Elas foram agrupadas segundo o critério estabele- cido pela "Classificação Setorial Bovespa". Os segmentos foram selecionados arbitrariamente em que se buscou incluir segmentos regulados, mais competitivos, de serviços, somente empresas privadas, misto públicas e privadas etc. Os resultados são apresentados em tabelas setoriais e, imediatamente após, analisam-se os mesmos. Algumas empresas dos sub-grupos constantes na classificação da Bovespa foram retiradas da amostra por não disporem de um apropriado número mínimo de anos para a realização do teste de causalidade de Granger.

\subsection{Carnes e Derivados}

Tabela 1 - Alimentos/carnes e derivados

\begin{tabular}{lccc} 
Empresa & Estatística F & Probabilidade & Hipótese Corroborada \\
Avipal & & & H4 \\
\hline Preço não granger causa custo & 1.09393 & 0.45001 & H3 \\
\hline Custo não granger causa preço & 1.49183 & 0.33123 & \\
\hline Sadia & & & H3 \\
\hline Preço não granger causa custo & 5.85266 & $0.02044^{\star *}$ & \\
\hline Custo não granger causa preço & 7.37400 & $0.01086^{* \star}$ & \\
\hline Seara & & $0.00368^{\star \star *}$ & \\
\hline Preço não granger causa custo & 10.5954 & $0.07466^{*}$ & \\
\hline Custo não granger causa preço & 3.38252 & & \\
\hline${ }^{*}$ significante a $10 \%,{ }^{* *}$ significante a $5 \%,{ }^{* * *}$ significante a $1 \%$. & & \\
\hline
\end{tabular}

O setor de alimentos, nessa amostra, é composto de três empresas. Elas foram as únicas constantes do sub-grupo carnes e derivados da classificação setorial da BOVESPA e que dispunham de dados no software Economática ${ }^{\mathrm{TM}}$.

No caso da Avipal não foi possível determinar qualquer causalidade entre as variáveis preço e custo. A hipótese de independência pode ser fruto da falta de uma estratégia claramente definida e implementada pela empresa (custo-meta ou custo mais margem) ou, simplesmente, a incapacidade do teste de causalidade de Granger de captá-la.

Esse último caso, poderia ser, por exemplo, conseqüência da obtenção de dados trimestrais enquanto a empresa tem uma estratégia que envolve análise de períodos mais curtos. Essa interpretação fica um pouco prejudicada devido ao fato de que as outras duas empresas constantes na amostra apresentaram bicausalidade definida, inclusive com $1 \%$ de significância estatística.

A interdependência entre preço e custo das empresas Sadia e Seara poderia sugerir que as empresas desse setor comportam-se competitivamente algumas vezes e, em outras, podem usufruir os benefícios de um certo poder de mercado devido ao número restrito de competidores significativos. De fato, a hipótese de independência das variáveis de uma empresa e interdependência das demais pode sugerir uma oscilação de padrões difícil de ser captada nos testes.

Finalmente, nesse caso, uma análise das estratégias adotadas por essas empresas, em particular o custo-meta, mereceria uma análise complementar do setor externo, já que as empresas têm uma parcela significativa de exportação nas suas vendas totais.

\subsection{Construção}

Três empresas nesse segmento - Chiarelli, Demellot e Portobello - tiveram como resultado a quarta hipótese, ou independência das variáveis preço e custo dos produtos vendidos. Uma empresa, Eternit, acusou a primeira hipótese de que preço determina custo, ou custo-meta. Uma única empresa, Itaú, acusou a segunda hipótese, ou custo mais margem. 
Tabela 2- Construção

\begin{tabular}{|c|c|c|c|}
\hline Empresa & Estatística F & Probabilidade & Hipótese Corroborada \\
\hline Chiarelli & & & H4 \\
\hline Preço não granger causa custo & 0.09796 & 0.95952 & \\
\hline Custo não granger causa preço & 0.31273 & 0.81589 & \\
\hline Demellot & & & H4 \\
\hline Preço não granger causa custo & 0.77146 & 0.53850 & \\
\hline Custo não granger causa preço & 0.74352 & 0.55261 & \\
\hline Eternit & & & H1 \\
\hline Preço não granger causa custo & 2.36210 & $0.09191^{\star}$ & \\
\hline Custo não granger causa preço & 2.08693 & 0.12485 & \\
\hline Itaú & & & H2 \\
\hline Preço não granger causa custo & 0.79245 & 0.54528 & \\
\hline Custo não granger causa preço & 3.09309 & $0.04208^{\star *}$ & \\
\hline Portobello & & & H4 \\
\hline Preço não granger causa custo & 0.24488 & 0.90901 & \\
\hline Custo não granger causa preço & 1.77357 & 0.17816 & \\
\hline
\end{tabular}

Cabe ressaltar, entretanto, que a empresa que acusou a primeira hipótese, de que preço determina custo, teve seu resultado aceito com $10 \%$ de margem de erro, ou significância estatística (F estimado em 2.36210 e probabilidade de 0.09191). Portanto, a mesma estava no limite entre a primeira e a quarta hipótese.

De fato, se, a critério do analista, fosse adotado os 5\% com margem de erro aceitável, a Eternit, também, obteria como resultado a quarta hipótese de independência das variáveis. Assim, a hipótese de independência seria observada em $80 \%$ das empresas pesquisadas. A empresa restante, Itaú, evidencia a hipótese de que custo determina preço.

Esses resultados combinados podem sugerir que não existe uma estratégia definida no setor, particularmente a de custo-meta. Uma hipótese alternativa é a de que uma empresa tem poder de mercado maior que as demais, ou até mesmo liderança de preço. Esse seria o caso da empresa que apresentou resultados de que os custos determinam os preços, ou custo mais margem.

Uma análise mais robusta desses resultados demandaria uma coleta de informações com relação à fatia de mercado de cada empresa, a existência ou não de fidelização dos clientes, e, até, a sua distribuição geográfica.

\subsection{Distribuição de Petróleo}

Tabela 3- Distribuição de Petróleo

\begin{tabular}{lccc} 
Empresa & Estatística F & Probabilidade & Hipótese Corroborada \\
BR Distribuidora & & & H4 \\
\hline Preço não granger causa custo & 1.04754 & 0.41047 & H2 \\
\hline Custo não granger causa preço & 0.75327 & 0.56883 & \\
\hline Ipiranga Distribuidora & & 0.20366 & \\
\hline Preço não granger causa custo & 1.65695 & $0.09435^{*}$ & \\
\hline Custo não granger causa preço & 2.33840 & &
\end{tabular}


Esse setor é constituído de apenas duas empresas com dados disponíveis para análise. A BR Distribuidora apresentou como resultado a independência entre as variáveis preço e custo dos produtos vendidos. De fato, não chega a ser um resultado surpreendente. A mesma é uma subsidiária da Petrobrás, objeto de estudo no grupo de exploração e refino de petróleo. Adianta-se, aqui, que lá a Petrobras, também, apresentou a quarta hipótese como resultado. O resultado não surpreende, em ambos os casos, pois a política de estabelecimento de preços pela $\mathrm{Pe}$ como uma "caixa-preta", que eventualmente mistura trobrás é altamente questionada e sendo conhecida

influências políticas governamentais com influências da burocracia interna da empresa.

A segunda empresa, Ipiranga Distribuidora, apresentou como resultado a segunda hipótese, com $10 \%$ de significância, ou seja, no limite estatístico entre a segunda e quarta hipótese. Pode-se interpretar, aqui, que a empresa dispõe de um certo poder de mercado embora inserida num mercado em que a líder não dispõe de uma estratégia de preços e custos claramente observáveis.

\subsection{Eletrodomésticos}

Tabela 4- Eletrodomésticos

\begin{tabular}{lccc} 
Empresa & Estatística F & Probabilidade & Hipótese Corroborada \\
Electrolux & & & H4 \\
\hline Preço não granger causa custo & 0.10581 & 0.97926 & 0.70861 \\
\hline Custo não granger causa preço & 0.53905 & & H4 \\
\hline Gradiente & & 0.51673 & H2 \\
\hline Preço não granger causa custo & 0.83750 & 0.68443 & \\
\hline Custo não granger causa preço & 0.57413 & & \\
\hline Multibrás & & 0.46535 & \\
\hline Preço não granger causa custo & 0.92871 & $0.08969^{*}$ & \\
\hline Custo não granger causa preço & 2.31161 & & \\
\hline
\end{tabular}

As empresas com dados disponíveis para análise, embora sejam apenas três - Gradiente, Electrolux e Multibrás - , podem ser consideradas representativas no setor.

Electrolux e Gradiente apontaram a quarta hipótese como resultado. Esses resultados podem sugerir uma estratégia de preços não claramente definida ou simplesmente não implementada com

sucesso. A Multibrás evidenciou a segunda hipótese com resultado do teste, ou seja, de que custo determina preço ou custo mais margem. Ressaltese que essa empresa resultou da aquisição de outra empresa do setor; é natural, assim, observar-se certo poder de mercado de sua parte.

\subsection{Energia Elétrica}

Tabela 5- Energia Elétrica

\begin{tabular}{llcc} 
Empresa & Estatística F & Probabilidade & Hipótese Corroborada \\
AES Tiete & & & H4 \\
\hline Preço não granger causa custo & 0.09796 & 0.95952 & H1 \\
\hline Custo não granger causa preço & 0.31273 & 0.81589 & \\
\hline Demellot & & & $0.00102^{* *}$ \\
\hline Preço não granger causa custo & 15.7488 & 0.76504 & \\
\hline Custo não granger causa preço & 0.38776 & &
\end{tabular}

Continua 
Continuação

\begin{tabular}{|c|c|c|c|}
\hline Empresa & Estatística F & Probabilidade & Hipótese Corroborada \\
\hline AES Sul & & & H4 \\
\hline Preço não granger causa custo & 0.33292 & 0.80185 & \\
\hline Custo não granger causa preço & 1.17778 & 0.36252 & \\
\hline CESP & & & H4 \\
\hline Preço não granger causa custo & 0.65110 & 0.59861 & \\
\hline Custo não granger causa preço & 0.33735 & 0.79877 & \\
\hline Elektro & & & H4 \\
\hline Preço não granger causa custo & 1.54840 & 0.27708 & \\
\hline Custo não granger causa preço & 0.30497 & 0.86683 & \\
\hline Eletropaulo & & & H1 \\
\hline Preço não granger causa custo & 2.81973 & $0.08825^{\star}$ & \\
\hline Custo não granger causa preço & 0.41051 & 0.74869 & \\
\hline Light & & & H4 \\
\hline Preço não granger causa custo & 0.20224 & 0.93011 & \\
\hline Custo não granger causa preço & 0.05686 & 0.99277 & \\
\hline RGE & & & H1 \\
\hline Preço não granger causa custo & 3.54315 & $0.05159^{*}$ & \\
\hline Custo não granger causa preço & 0.79687 & 0.52092 & \\
\hline
\end{tabular}

Das oito empresas com dados disponíveis para análise, nesse setor, cinco apresentaram como resultado a quarta hipótese ou de independência entre preço e custo. As demais três empresas - Demellot, Eletropaulo e RGE - apresentaram como resultado a primeira hipótese, de que preço determina custo. Dessas três, a Demellot teve a primeira hipótese aceita com margem de erro de apenas $1 \%$, a RGE praticamente em $5 \%$ e a Eletropaulo em $10 \%$, o que a colocou no limite estatístico entre a primeira e quarta hipótese, predominante no setor.

Nesse setor, os preços são autorizados e fiscalizados pela agência reguladora ANEEL. É possível, aqui, que algumas empresas inflem os custos para obterem uma autorização de repasse maior e que a mesma não seja concedida pela agência reguladora. Também é possivel, aliás provável, que seja um setor muito suscetível a influências políticas e externas, por exemplo, ao "apagão" de 2001, em que as distribuidoras não obtiveram energia das geradoras para vender.

A predominância da quarta hipótese não deixa de ser um padrão interessante para o setor. Aqui, o que realmente demandaria um estudo de caso é a empresa Demellot. Essa distribuidora apresentou como resultado a primeira hipótese, ou custo-meta, com menos de $1 \%$ de margem de erro. É possível que a empresa procure antecipar as decisões da agência reguladora e direcione sua estratégia para obter um lucro em cima dos preços estabelecidos através da redução de custos. A existência ou não do custo-meta, e o papel da contabilidade nessa empresa, merecem uma pesquisa in loco adicional.

\subsection{Fios e Tecidos}

Nesse setor, do total de dezessete empresas analisadas, treze evidenciaram como resultado do teste de causalidade de Granger a quarta hipótese, a de independência entre as variáveis preço e custo dos produtos vendidos. Independência no sentido de que não foi possível estabelecer um padrão estatisticamente significante entre as variáveis. Novamente, esse resultado pode ter sido fruto da impossibilidade do teste de captar padrões mais 
Tabela 6- Fios e Tecidos

\begin{tabular}{|c|c|c|c|}
\hline Empresa & Estatística F & Probabilidade & Hipótese Corroborada \\
\hline Cedro & & & H4 \\
\hline Preço não granger causa custo & 1.73723 & 0.24562 & \\
\hline Custo não granger causa preço & 0.40397 & 0.80069 & \\
\hline Círculo & & & H4 \\
\hline Preço não granger causa custo & 0.31598 & 0.85879 & \\
\hline Custo não granger causa preço & 0.42605 & 0.78607 & \\
\hline Coteminas & & & H4 \\
\hline Preço não granger causa custo & 1.81160 & 0.23119 & \\
\hline Custo não granger causa preço & 2.08145 & 0.18684 & \\
\hline Cremer & & & H4 \\
\hline Preço não granger causa custo & 0.56940 & 0.69367 & \\
\hline Custo não granger causa preço & 1.17545 & 0.39839 & \\
\hline Dohler & & & H1 \\
\hline Preço não granger causa custo & 6.53265 & $0.01630^{\star \star}$ & \\
\hline Custo não granger causa preço & 1.03869 & 0.45097 & \\
\hline F Guimarães & & & H4 \\
\hline Preço não granger causa custo & 1.16959 & 0.36933 & \\
\hline Custo não granger causa preço & 0.50320 & 0.68860 & \\
\hline Jaraguá & & & H4 \\
\hline Preço não granger causa custo & 0.01196 & 0.91597 & \\
\hline Custo não granger causa preço & 0.77088 & 0.40907 & \\
\hline Karsten & & & H4 \\
\hline Preço não granger causa custo & 2.25102 & 0.16431 & \\
\hline Custo não granger causa preço & 1.76425 & 0.24025 & \\
\hline Pettenatti & & & H2 \\
\hline Preço não granger causa custo & 1.71476 & 0.22677 & \\
\hline Custo não granger causa preço & 5.56063 & $0.01659^{* *}$ & \\
\hline Renaux & & & H1 \\
\hline Preço não granger causa custo & 3.72587 & $0.06240^{*}$ & \\
\hline Custo não granger causa preço & 0.82032 & 0.55132 & \\
\hline Santanense & & & H4 \\
\hline Preço não granger causa custo & 0.67514 & 0.58674 & \\
\hline Custo não granger causa preço & 0.31574 & 0.81381 & \\
\hline
\end{tabular}




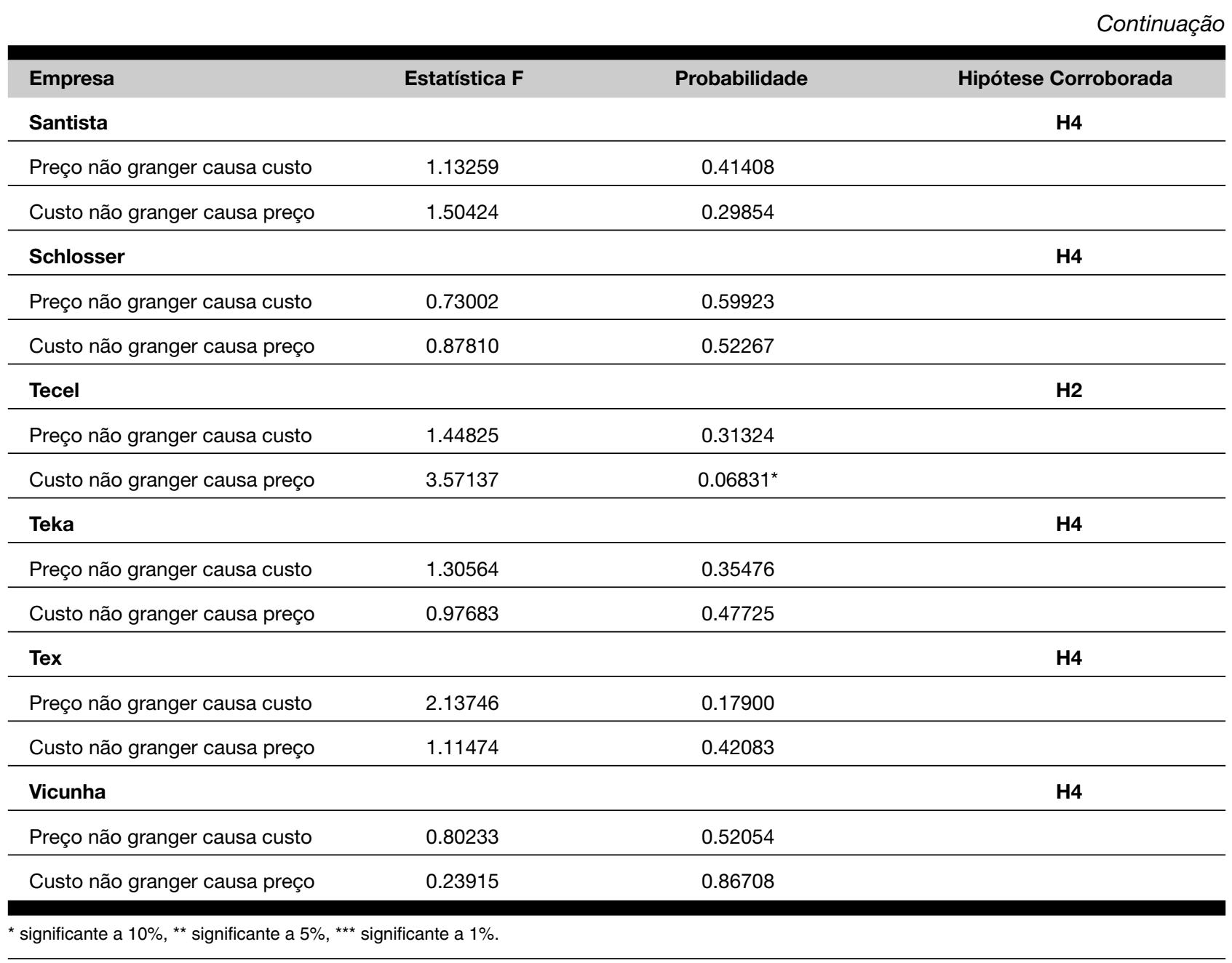

sutis entre as variáveis preço e custo. Isso poderia ser resultado, eventualmente, da necessidade de se apurarem os dados em intervalos de tempo reduzidos. Infelizmente, isso não é uma possibilidade com os dados oriundos dos balanços trimestrais.

Uma segunda hipótese é a de que o teste não foi capaz de captar um padrão nas empresas analisadas porque não possuem estratégias de preços-custos claramente definidas e implementadas. Alterações conjunturais ou oscilações administrativas podem alterar o planejamento previamente estabelecido pela gerência da empresa. As incertezas inerentes prejudicam a estratégia da empresa. Nessa hipótese, o teste não é falho, mas simplesmente não existe algo para ser captado através da causalidade de Granger.

Duas empresas, Petenatti e Tecel, evidenciaram a segunda hipótese, a de que custos determinam preços. No caso da Tecel, o nível de significância foi de $10 \%$, ou próximo do limite da quarta hipótese, a de independência das variáveis. A empresa Pettenatti, por sua vez, apresentou um nível de significância muito bom, entre 5 e $1 \%$. Uma possível explicação para esse fenômeno é que essa empresa, por ser uma marca tradicional, conseguiu fidelizar seus clientes. Isso é, a empresa conseguiu um diferencial que torna a demanda por seus produtos menos sensível às atitudes dos concorrentes. Conseqüentemente, isso possibilita uma estratégia do tipo custo mais margem.

As empresas restantes, Dohler e Renaux, evidenciaram a primeira hipótese de que os preços dos produtos vendidos determinam os custos de produção, ou custo-meta. O caso da empresa Dohler é interessante, pois apresentou resultado bastante significativo. A hipótese inerente é que essas empresas conseguiram estabelecer uma estratégia competitiva. O teste de Granger, aqui, serve, no mínimo, para priorizar essas empresas em um futuro estudo de caso.

\subsection{Papel e Celulose}

Nesse setor, três empresas - Bahia Sul, Ripasa e Suzano - evidenciaram a quarta hipótese de independência entre as variáveis preço e custo. Duas empresas, Celulose Irani e Votorantim, evidenciaram a terceira hipótese de interdependência, 
Tabela 7- Papel e Celulose

\begin{tabular}{|c|c|c|c|}
\hline Empresa & Estatística F & Probabilidade & Hipótese Corroborada \\
\hline Aracruz & & & H2 \\
\hline Preço não granger causa custo & 0.82579 & 0.53184 & \\
\hline Custo não granger causa preço & 5.70313 & $0.00709^{\star \star *}$ & \\
\hline Bahia Sul & & & H4 \\
\hline Preço não granger causa custo & 0.35340 & 0.83712 & \\
\hline Custo não granger causa preço & 1.75902 & 0.19727 & \\
\hline Celulose Irani & & & H3 \\
\hline Preço não granger causa custo & 2.83658 & $0.07348^{\star}$ & \\
\hline Custo não granger causa preço & 5.30883 & $0.01077^{\star \star}$ & \\
\hline Ripasa & & & H4 \\
\hline Preço não granger causa custo & 1.51977 & 0.25369 & \\
\hline Custo não granger causa preço & 2.15649 & 0.13143 & \\
\hline Suzano & & & H4 \\
\hline Preço não granger causa custo & 0.79334 & 0.55015 & \\
\hline Custo não granger causa preço & 2.09852 & 0.13931 & \\
\hline Votorantim & & & H3 \\
\hline Preço não granger causa custo & 2.72066 & $0.07894^{*}$ & \\
\hline Custo não granger causa preço & 3.52308 & $0.03929^{\star \star}$ & \\
\hline
\end{tabular}

ou bicausalidade, entre as variáveis preço e custo dos produtos vendidos. Uma empresa, Aracruz, evidenciou com mínima probabilidade de erro de que custo é determinante dos preços praticados.

É importante ressaltar que as duas empresas que evidenciaram a terceira hipótese de interdependência entre as variáveis preço e custo o fizeram com baixa significância de que preço determina custo e alta significância de que custo determina preço. Ou seja, se, a critério do pesquisador, fosse utilizado o índice de 5\% (ao invés de 10\%) para validade estatística, essas empresas acabariam por corroborar a segunda hipótese de que o custo dos produtos vendidos é que determina os preços praticados.

Em sendo assim, poder-se-ia obter um padrão típico para esse setor em que três empresas não acusaram uma estratégia típica entre preço e custo enquanto as outras três acusaram um padrão que sugere que os custos dos produtos vendidos é que determina os preços praticados. Uma melhor compreensão desse setor implica em quantificar o percentual de exportações e a fatia de mercado de cada empresa.

\subsection{Exploração e Refino}

O resultado demonstra que uma empresa, Ipiranga, corrobora a hipótese de interdependência entre as variáveis preço e custo, hipótese corroborada com alto nível de significância estatística. Outra empresa, Petrobras, aponta, similarmente ao caso da BR Distribuidora, para a hipótese de independência entre as variáveis. A empresa multinacional YPF aponta para a hipótese de que preço determina os custos, embora no limite estatístico com a quarta hipótese de independência entre as variáveis.

Tal como no caso da exploração e refino de petróleo, esse setor sofre as influências políticas conjunturais. Por exemplo, a própria YPF já teve um pré-acordo para aquisição de algumas refinarias da Petrobrás. Hoje a YPF possui participação acionária minoritária e o novo governo sugere a reestatização total das refinarias parcialmente privatizadas. Adiciona-se que a Petrobrás, líder absoluta do mercado, fruto de décadas de monopólio no setor, tem uma política de preços obscura até mesmo para os analistas do mercado. 
Tabela 8- Exploração e Refino

\begin{tabular}{lccc} 
Empresa & Estatística F & Probabilidade & Hipótese Corroborada \\
Ipiranga & & & H3 \\
\hline Preço não granger causa custo & 5.05014 & $0.00484^{\star \star \star}$ & H4 \\
\hline Custo não granger causa preço & 7.45569 & $0.00059^{\star \star \star}$ & \\
\hline Petrobrás & & & H1 \\
\hline Preço não granger causa custo & 0.20879 & 0.93078 & 0.49384 \\
\hline Custo não granger causa preço & 0.87655 & & $0.08627^{*}$ \\
\hline YPF & & 0.32694 & \\
\hline Preço não granger causa custo & 2.34478 & & \\
\hline Custo não granger causa preço & 1.22997 & & \\
\hline
\end{tabular}

\section{CONCLUSÃO}

O objetivo deste trabalho foi avaliar em que extensão a estratégia do custo-meta está sendo utilizada pelas empresas brasileiras. A literatura, nacional e internacional, em sua maioria, tem adotado os estudos de casos. Fundamental, aqui, foi a utilização do método de causalidade de Granger em que quatro hipóteses foram testadas, quais sejam: a) preço determina custo dos produtos vendidos (custo-meta); b) o custo de produção determina o preço de venda (custo mais margem); c) existe bicausalidade entre preço e custo (interdependência); d) as variáveis são independentes estatisticamente.

Das quarenta e sete empresas analisadas, vinte e nove evidenciaram a quarta hipótese (independência), sete empresas a primeira hipótese (custometa), sete empresas a segunda hipótese (custo mais margem) e quatro a terceira hipótese (bicausalidade). As empresas foram distribuídas em oito grupos setoriais com o intuito de identificar alguma estratégia dominante em determinado grupo.

A primeira hipótese não apareceu nos setores de carne e derivados, distribuição de petróleo, eletrodomésticos e papel e celulose. Nos demais grupos, a hipótese do custo-meta apareceu, significativamente, no setor de energia e distribuição. Nesse setor, $37.5 \%$ das empresas evidenciaram a hipótese do custometa. Esse setor tem duas características marcantes: a regulação e a participação de multinacionais. Pode-se supor que as empresas antecipam os preços autorizados da agência reguladora e fixam metas de redução de custos para atingir o lucro desejado. Essa suposição deve ser reparada pelas constantes interferências políticas no setor. $O$ fato de serem multinacionais pode facilitar a implementação da estratégia devido ao know how externo em termos de gestão.
A segunda hipótese, custo mais margem, somente não apareceu nos setores de distribuição de energia e carne e derivados. Nos demais setores, a segunda hipótese apareceu de forma dispersa. Pode-se supor que, de fato, muitos setores têm se deparado com um ambiente mais competitivo e, portanto, não podem mais simplesmente adicionar uma margem de lucro sobre os custos e esperar que os consumidores paguem.

A terceira hipótese, da interdependência das variáveis, apareceu em apenas 4 empresas do estudo. Duas vezes no setor de carne e derivados e duas vezes no setor de papel e celulose. Esses resultados podem sugerir que as empresas oscilam entre uma e outra estratégia de preço. Eventualmente, usufruem um certo poder de mercado e outras vezes atuam mais competitivamente. Ressalte-se, aqui, que tanto o setor de carne e derivados quanto o de papel e celulose exportam uma parcela significativa de seus produtos. Uma análise adicional do mercado externo seria apropriada.

A quarta hipótese, a independência entre as variáveis preço e custo, foi predominante no estudo. Aqui se abrem duas linhas de explicação possíveis. Primeira, de que o teste não foi capaz de captar um padrão dessas variáveis nessas empresas. $O$ teste não indica que não exista relação entre as variáveis, mas sim que não é possível estabelecer um padrão com uma margem de erro estatisticamente confiável. Segunda, que de fato essas empresas não dispõem de uma estratégia de atuação claramente definida, ou ainda, mesmo que a disponham, não conseguiram implementar. A hipótese da incerteza e oscilações é inerente a esses resultados.

Nessa conclusão, executou-se uma análise das hipóteses. Na seção cinco deste artigo, analisaram-se, criticamente, os resultados apresentados 
por cada um dos oito setores. Muitas variáveis ainda devem ser consideradas, tais como o grau de competitividade no setor, as influências externas de mercado ou políticas etc. A periodicidade dos dados pode ser muito importante aqui. Essa análise deve ser interpretada mais como um "filme" que necessita de continuação do que "fotografias estáticas". No futuro, pode-se identificar, por exemplo, quantas empresas que adotaram a primeira estratégia e foram bem sucedidas, e quantas que adotaram a segunda e acabaram tendo maiores dificuldades.

Não obstante as limitações existentes, o trabaIho aqui desenvolvido e o método utilizado podem servir como um guia futuro para estudos de casos, ou seja, um primeiro filtro para posteriores análises detalhadas, quando, então, se incluiriam variáveis mercadológicas e internas da empresa, entre outras consideradas relevantes.

\title{
REFERÊNCIAS BIBLIOGRÁFICAS
}

BAHIA, L. D.. Grau de Monopólio e Testes de Granger Causalidade entre custos e preços na indústria brasileira (19781998). Texto para Discussão 770. IPEA, 2000.

BAFFES, J.; SHAH, A.. Causality and comovement between taxes and expenditures: historical evidence from Argentina, Brazil and Mexico. Journal of Development Economics 44, p. 311-31, 1994.

BONE, R. Bröker. Existe Causalidade entre as ações da Petrobrás Holding e o lbovespa entre 1994 e 2002? São Paulo, Resenha BMF\&F n. 155, 2003.

BORGERÑAS, Henrik; FRIDH, Gustav. The use of custo-meta in Swedish manufacuring firms. Göteborg, Department of Business Administration, 2003.

CARNEIRO, F.; FARIA, J.. Causality between the minimum wge and other wges. Applied Economics Letters, Forthcoming, 1996.

CONSELHO FEDERAL DE CONTABILIDADE-CFC. Princípios Fundamentais de Contabilidade. Brasília, 2000.

COOPER, Robin; CHEW, W. Bruce. Control tomorrow's costs through today's designs. Harvard Business Review, jan./feb., p. 88-97, 1996.

; SLAGMULDER, Regine. Targeting costing and value engineering. Montvale, IMA - Strategies in Confrontational Cost Management Series, 1997.

ENDERS, Walter. Applied Econometric time Series. New York: John Wiley \& Sons, 1995.
ENGLE, Robert; GRANGER, Clive. Cointegration and Error-Correction: Representation, Estimation, and Testing. Econometrica, vol. 55, p. 251-276, 1987.

FERREIRA, A.. Testes de Granger-causalidade para a balança comercial brasileira. Revista Brasileira de Economia, p. 83-95, 1993.

GRANGER, C.. Investigating Causal relations by econometric models and Cross-Spectral Methods, Econometrica, vol. 37, p. 424-438, 1969.

Some Recent Developments in a concept of causality, Journal of Econometrics, vol. 39, p. 199-211, 1988.

HORNGREN, Charles T., SUNDEM, Gary L., STRATON, William O.. Introduction to management accounting. Upper Saddle River, Prentice-Hall, 1996.

KENDALL, M.; STUART, A.. The advanced theory of statistics. New York: Charles Griffin Publishiers, 1961.

PINDYCK, Robert; RUBINFELD, Daniel. Econometric models and economic forecasts. Boston: McGraw-Hill, 1998.

PORTER, Michael. Vantagem competitiva. Rio de Janeiro, Campus, 1990.

SAKURAI, Michiharu. Gerenciamento integrado de custos. São Paulo: Atlas, 1997.

NOTA:

Endereço dos autores:

UNISINOS

Av. Unisinos, 950 - Cristo Rei

São Leopoldo - RS

93022-000

\author{
United Arab Emirates Universities \\ Dep. Of Economics \\ Al-Ain - Pox 17555
}

R. Cont. Fin. - USP, São Paulo, n. 39, p. 33 - 46, Set./Dez. 2005 